\title{
Growth, Reproduction, Mortality, and Pathologic Changes in Rats Fed Gamma-irradiated Potatoes $^{1}$
}

\author{
C. H. Burns, G. D. Abrams, and L. E. Brownell \\ From, respectively, Fission Products Laboratory; Medical School, Department of \\ Pathology; and College of Engineering; University of Michigan, Ann Arbor \\ Received June 10, 1959
}

The use of ionizing radiation to arrest sprout development in tubers and thereby prolong their storage life has been reported by Sparrow and Christensen (1954), Brownell et al. (1954, 1957), and others. Since only about 7-15 kilorads are required to achieve this, many of the problems involved in the sterilization of foods by radiation, which require doses of 4000 kilorads or more, are avoided. Accordingly, potatoes were one of the first irradiated food items to be evaluated for wholesomeness in the extensive program sponsored by the Office of the Surgeon General of the U. S. Army. In accordance with procedures set up by the Food and Drug Administration as reported by Lehman et al. (1955) the evaluation of wholesomeness was based upon the growth, food consumption, reproductive performance, longevity, and hematologic and pathologic changes in rats fed a diet containing $35 \%$, on a dry-weight basis, of the test potatoes for two years. In addition, growth and reproductive performance of second- and third-generation animals were to be determined. The following is a report on the experiment.

\section{METHODS}

\section{Source, Irradiation, and Storage of Potatoes}

The potato varieties selected for the test were Idaho Russet Burbanks, Maine Russet Burbanks, and Maine Katahdins, and they were used in equal quantities. Two dose ranges of $13.5-20$ and $27-40$ kilorads of gamma radiation from reactor fuel elements were tested on each variety. The higher level was to provide a test of potatoes given an overdose. The

1 We wish to acknowledge the support of the Office of the Surgen General, Department of the Army (Contract No. DA-49-007-MD-581) for the work herein reported. 
potatoes used during the first year of the feeding experiment were from the 1955 harvest and were irradiated in December at the National Reactor Test Site, Arco, Idaho. Those used during the second year were from the 1956 harvest.

The two varieties grown in Maine were subjected to shipping from that state to Idaho and back again for storage. All the potatoes from the first harvest and most of those from the second were stored after irradiation at Presque Isle, Maine. An additional quantity of second-year lots were stored in Idaho. Nonirradiated lots of each variety were treated identically, except for the irradiation step, to serve as controls, and these were manually desprouted as necessary. The controls will be referred to as " $0 \times$ " potatoes, and irradiated lots as " $1 \times$ " and " $2 \times$." After being shipped to Ann Arbor, Michigan, they were accommodated in a regular potatostorage locker held nominally at $40^{\circ} \mathrm{F}$. and in a household-type refrigerator until made into diet.

Three months after the potatoes had been irradiated, the fecding part of the experiment began. The skins and eyes as well as the whites were included in the potato diet. Decay began appearing a month later and the percentage increased steadily in potatoes received thereafter. Starting with the twenty-fifth week of feeding, all but traces of decay were culled and discarded. During the last 10 weeks of this 25 -week period, the amount of decay occurring in the potatoes and the proportion of decayed material included in the diet were estimated by weight. The results for the nine lots of potatoes are shown in Table 1 . With each variety there was a progressive increase in decay with the irradiation dose; the Katahdin variety appeared more susceptible than did the Burbank varieties. This

TABLE 1

Per Cent Decay by Weight Occurring in Potatoes and Included in the Diet from the Fifteenth to the Twenty-fifth Wee $\mathrm{K}$ of Feeding

\begin{tabular}{|c|c|c|c|}
\hline \multirow[b]{2}{*}{ Variety } & \multicolumn{3}{|c|}{$\begin{array}{l}\text { Irradiation } \\
\% \text { Decay }\end{array}$} \\
\hline & $0 x^{a}$ & $1 x^{*}$ & $2 \times^{a}$ \\
\hline Maine Katahdin & 0.7 & 5.4 & 8.3 \\
\hline Maine Russet Burbank & 1.4 & 2.6 & 3.8 \\
\hline Idaho Russet Burbank & 1.5 & 1.9 & 4.4 \\
\hline Whole diet ${ }^{b}$ & 0.9 & 2.4 & 3.9 \\
\hline
\end{tabular}


is consistent with the results obtained by Highlands (1958) in storage studies of irradiated potatoes.

\section{Diet Formulation and Preparation}

The composition of the diet is listed in Tabulation A.

Tabulation A

\begin{tabular}{lcc}
\hline \multicolumn{1}{c}{ Ingredients } & $\begin{array}{c}\text { Dry weight } \\
(\%)\end{array}$ & $\begin{array}{c}\text { Wet weight } \\
\text { (grams per batch) }\end{array}$ \\
\hline Maine Katahdin & 11.7 & 1300 \\
Maine Russet Burbank & 11.7 & 1300 \\
Idaho Russet Burbank & 11.7 & 1300 \\
Purified casein & 15 & 355 \\
Lactalbumin & 10 & 235 \\
Alphacel & 5 & 120 \\
Corn starch & 14 & 330 \\
Lard & 15 & 355 \\
Salt mixture & 3.5 & 84 \\
Vitamin mixture & 0.85 & 20 \\
Choline chloride & 0.2 & 4.7 \\
Cod liver oil & 1.0 & 24 \\
\hline
\end{tabular}

The use of $1300 \mathrm{~g}$ of each variety per batch is based on an average dry weight of $21 \%$ of all varieties as determined by oven-dried samples of various batches at this laboratory over a period of several weeks. The vitamin mixture was added to the diet at a level of $0.85 \%$ (20 g per batch) and had the composition given in Tabulation $\mathbf{B}$.

Tabulation B

\begin{tabular}{lc}
\hline \multicolumn{1}{c}{ Vitamins } & $\mathrm{g} / \mathrm{kilo}$ \\
\hline Inositol & 5.0 \\
Menadione & 2.25 \\
p-Aminobenzoic acid & 5.0 \\
Niacin & 4.5 \\
Riboflavine & 1.0 \\
Thiamine HCl & 1.0 \\
Calcium pantothenate & 3.0 \\
& $\mathrm{mg} / \mathrm{kilo}$ \\
Biotin & 20 \\
Folic acid & 90 \\
Vitamin B B2 $_{2}$ & 1.35 \\
& $\mathrm{~g} / \mathrm{kilo}$ \\
Extender (casein) & 974 \\
\hline
\end{tabular}


After the first year of the experiment, the thiamine and biotin levels were increased twofold and the riboflavine level, threefold. These increases were made because of an ocular inflammation in the animal colony which may have been caused by marginal levels of these vitamins.

Since the potatoes in the diet furnished over $1 \%$ potassium on a dryweight basis (Sherman, 1946), it was desirable not to furnish additional potassium through the salt mixture. The salt mixture therefore had the following composition: $\mathrm{CaHPO}_{4} \cdot 2 \mathrm{H}_{2} \mathrm{O}, 48.0 \% ; \mathrm{NaCl}, 22.1 \% ; \mathrm{CaCO}_{3}$, $15.0 \% ; \mathrm{MgSO}_{4} \cdot 7 \mathrm{H}_{2} \mathrm{O}, 8.7 \% ; \mathrm{Fe}$ citrate $\cdot 6 \mathrm{H}_{2} \mathrm{O}, 5.5 \% ; \mathrm{MnSO}_{4} \cdot \mathrm{H}_{2} \mathrm{O}$, $0.52 \% ; \mathrm{KI}, 0.08 \% ; \mathrm{CuSO}_{4} \cdot 5 \mathrm{H}_{2} \mathrm{O}, 0.07 \%$.

After one year of the experiment, calcium carbonate was removed from the salt mixture because of the possibility that it was promoting autooxidation of some of the vitamins (Waibel et al., 1954). The calcium was replaced by additional calcium phosphate.

The potatoes, after being freed of decay (except during the first few months of feeding), were rinsed off, cut up, and steamed for 10-15 minutes at low steam pressure. They were then forced through a meat grinder having a plate with $3 / 16$-inch-diameter holes. The dry ingredients, melted lard, and other liquids were added to the cooked and mashed potatoes, and the mixture was beaten to the consistency of a dough. This was rolled out in a flat stainless-steel pan and stored under refrigeration for not more than 2 days.

\section{The Animal Colony}

The parent-generation colony was divided into five replicates. Each replicate consisted of five litters of Holtzmann strain rats (Madison, Wisconsin), each with four males and four females. The replicates were started 1 week apart, the first on 14 March, 1956. All rats were 22 days old when started. Each of the three potato diets was fed to one male and one female in each of the twenty-five litters. The groups thus constituted will be referred to as the " $O X, "$ " $1 \times$," and " $2 \times$ " groups. The fourth male and fourth female in each litter were fed Purina Laboratory Chow, and these animals will be referred to as the "XL" (extralittermate) group.

The parent generation of animals was maintained for two years. At 15 weeks of age, four of the five females fed each diet in each replicate were mated in weekly rotation with four males in the same group. This was repeated, and the animals obtained from the second breeding of the parents were fed the parental diet until they, in turn, had undergone two breedings. After this they were no longer maintained for the purposes of 
this experiment. They were then continued on the $0 \times$ diet, and later, on the same diet with fresh market potatoes, to make certain observations of pathological interest (Burns and Abrams). The third-generation animals were also fed the experimental diets until their young had been weaned, at which time they too were continued on the fresh-potato diet. The fourth-generation animals were examined at weaning, but were not fed the irradiated-potato diet thereafter.

All animals fed the irradiated potato diets were housed in individual wire-bottom cages and provided with water and diet ad libitum. Animals fed Purina Laboratory Chow were housed five to a large cage, and were not mated. The animals' quarters were air conditioned $\left(70^{\circ} \mathrm{F}\right)$, ambient humidity prevailing.

\section{Procedures Used}

All animals were weighed weekly to the nearest gram.

Food consumption was measured for the first 12 weeks after weaning for first- and second-generation animals. Each animal's daily allotment of fresh food was weighed, and samples from the same batch of diet were air-dried to constant weight. Food left in jars was collected daily and combined, after fecal matter was separated, with food spilled, which was caught on a piece of mosquito screen; this was dried in air and its weight was subtracted from the total of food, dry basis, fed for the week as calculated from the daily fresh-food weights and fraction of solids.

Reproduction data consisted of apparent pregnancies, pups born per litter, survival of pups to first and twenty-first days, and average body weights of pups at the seventh and fourteenth days of lactation for the last three of the six breedings, and at the twenty-first day for all breedings.

Blood cell counts were made on one male and one female in each of the three dietary groups in each of the five replicates (i.e., 30 animals of the total colony of 150). Blood was obtained from the tail vessels. These counts were performed during the fourth, tenth, and eighteenth months of the experiment.

All first-generation animals, whether found dead, sacrificed because of moribund condition, or sacrificed to terminate the experiment, were subjected to complete necropsy. The tissues were submitted for histologic examination to members of the Department of Pathology of the University of Michigan Medical School. Also included were members of the second generation which died or were sacrificed before the end of their second breeding period. 


\section{RESULTS}

\section{Growlh}

Growth curves for the first-, second-, and third-generation males and females fed the diets containing nonirradiated $(0 \times)$ potatoes and potatoes irradiated at two levels $(1 \times$ and $2 \times)$ are shown in Fig. 1. Body-

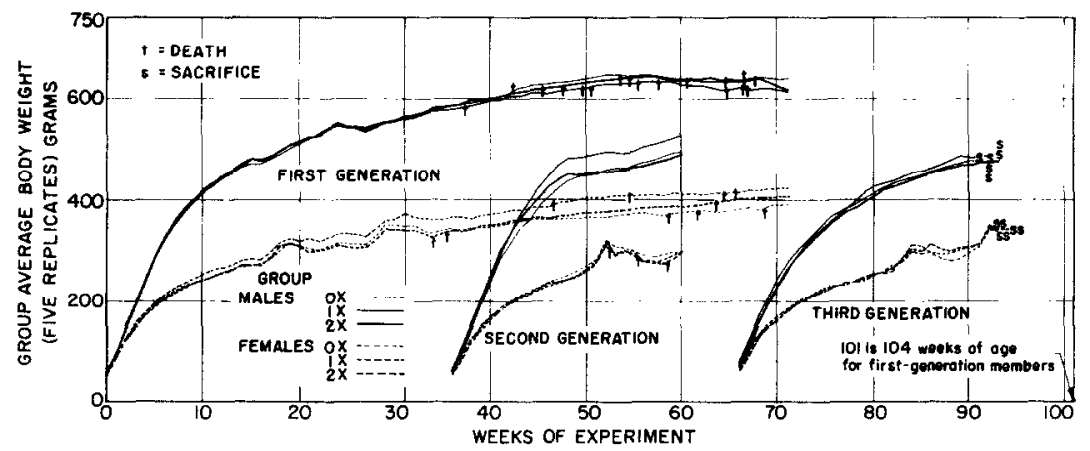

Frc. 1. Growth curves for first-, second-, and third-generation male and female rats fed diets containing irradiated potatoes.

weight averages for the first generation are extended beyond the growth and reproduction phase to about 70 weeks, at which time the mortality complicates the significance of the curves. Differences between the curves would not be significant for females after the onset of pregnancy.

The three diets resulted in uniform growth, except first-generation females fed the $1 \times$ diet, which showed a slight but statistically $(P=0.01)$ significant superiority in body weight. Table 2 shows means and standard deviations for first-generation animals up to 36 weeks and shows the small but significant increase in weight of $1 \times$ females but of no other groups.

\section{Food Efficiency}

The average gram body-weight gain per gram diet solids consumed for the 25 animals in each of the six groups is shown in Fig. 2 for the first 12 weeks following weaning. After 8 weeks, the fraction of food contributing to body-weight increase is small and normal fluctuations in growth rate lead to large differences in food efficiency. For the first 8 weeks, however, there is apparently no difference in the efficiency of each diet in furnishing nutrition for optimum growth. 


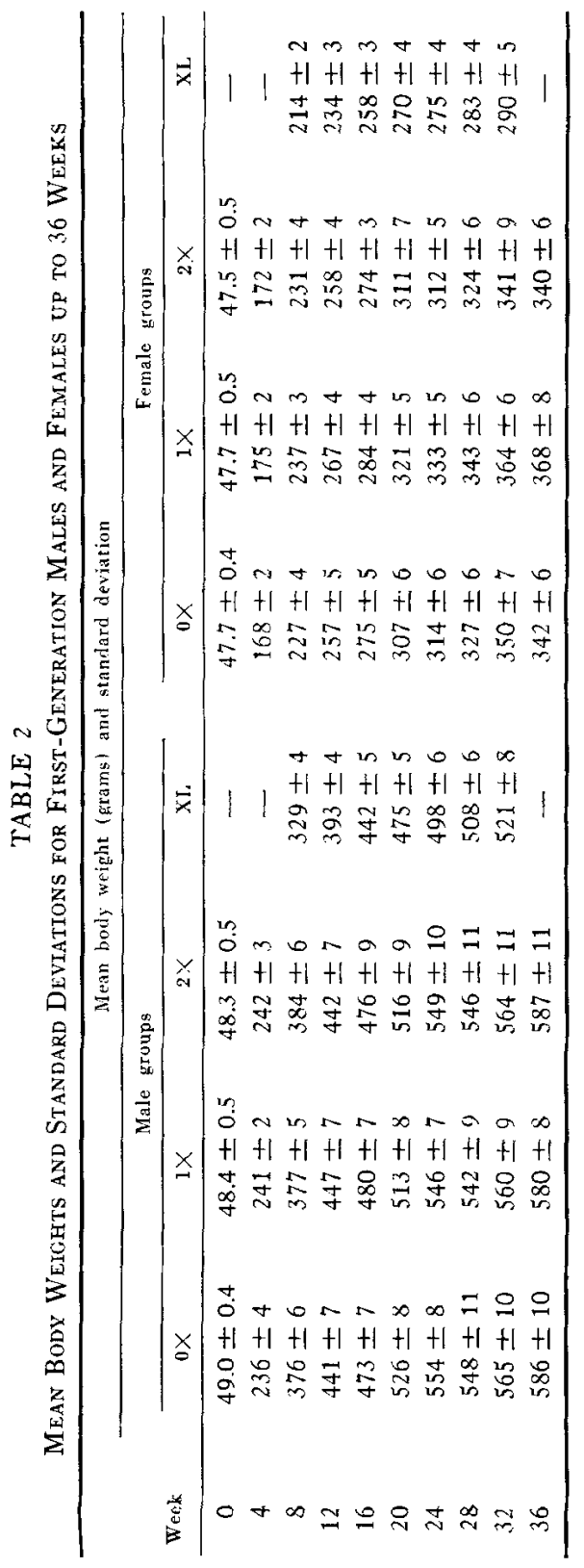


TABLE 3

Reproductive Performance of First, Second-, and Timrd-Generation Animals

\begin{tabular}{|c|c|c|c|c|c|c|c|}
\hline & & & & st.genera & anim & & \\
\hline & Breeding: & & First & & & Eecond & \\
\hline & Diet: & $0 x$ & $1 x$ & $2 \times$ & $0 . x$ & $1 x$ & $2 x$ \\
\hline 1 . & Number of females bred & 20 & 20 & 19 & 20 & 20 & 19 \\
\hline & Number of males used & 20 & 20 & 20 & 20 & 20 & 20 \\
\hline & $\begin{array}{l}\text { Per cent of females bred which } \\
\text { appeared to become pregnant }\end{array}$ & 90 & 90 & 95 & 85 & 75 & 84 \\
\hline & $\begin{array}{l}\text { Per cent of apparently pregnant } \\
\text { females which gave birth }\end{array}$ & 83 & 83 & 100 & 82 & 67 & 81 \\
\hline & $\begin{array}{l}\text { Average number of pups born } \\
\text { per litter }\end{array}$ & 11.2 & 9.6 & 10.7 & 10.4 & 11.9 & 10.5 \\
\hline 6. & $\begin{array}{l}\text { Per cent of pups bern surviving } \\
\text { birth and the first day after } \\
\text { birth }\end{array}$ & 80 & 78 & 77 & 86 & 92 & 95 \\
\hline & $\begin{array}{l}\text { Per cent of pups surviving the } \\
\text { first day which reached } 21 \\
\text { days (weaning) }\end{array}$ & 93 & 86 & 92 & 86 & 86 & 84 \\
\hline & $\begin{array}{l}\text { Average body weight of pups } \\
\text { at } 7 \text { days }\end{array}$ & - & - & - & - & - & - \\
\hline & $\begin{array}{l}\text { Average body weight of pups } \\
\text { at } 14 \text { days }\end{array}$ & - & - & - & - & - & - \\
\hline 10. & $\begin{array}{l}\text { Average body weight of pups at } \\
\text { weaning }\end{array}$ & 51.4 & 53.7 & 52.9 & 50.1 & 47.0 & 48.1 \\
\hline
\end{tabular}

\section{Reproduction}

Table 3 shows the reproductive performance for the first-, second-, and third-generation animals through the first and second breedings. Some differences can be found among animals in the three dietary groups. Apparent pregnancy was lowest for $1 \times$ females through all six breedings, and in the three instances where one group showed a relatively poor birth rate, this was always the $1 \times$ group. The average number of pups surviving to 1 day after birth was lower for first breedings than the second, and it was especially low during the first breedings of the first and third generations; but there were no differences among dietary groups in this respect. The number of pups surviving to weaning was variable from breeding to breeding and was particularly poor during the first breeding of the second and third generations. All groups, however, behaved in a 
TABLE 3 (Continued)

\begin{tabular}{|c|c|c|c|c|c|c|c|c|c|c|c|}
\hline \multicolumn{6}{|c|}{ Second-generation animals } & \multicolumn{6}{|c|}{ Third-seneration animals } \\
\hline \multicolumn{3}{|c|}{ First } & \multicolumn{3}{|c|}{ Second } & \multicolumn{3}{|c|}{ First } & \multicolumn{3}{|c|}{ Second } \\
\hline $0 x$ & $1 \times$ & $2 x$ & $0 \times$ & $1 \times$ & $2 \times$ & $0 x$ & $1 x$ & $2 \times$ & $0 \times$ & $1 x$ & $2 \times$ \\
\hline 20 & 19 & 20 & 19 & 18 & 18 & 20 & 20 & 20 & 20 & 20 & 20 \\
\hline 10 & 10 & 10 & 10 & 10 & 9 & 20 & 20 & 20 & 20 & 20 & 20 \\
\hline 00 & 84.2 & 100 & 94.7 & 77.7 & 94.4 & 100 & 95 & 100 & 100 & 95 & 100 \\
\hline 00 & 87.5 & 95.0 & 100 & 85.7 & 100 & 95 & 100 & 95 & 100 & 100 & 100 \\
\hline 10.9 & 10.3 & 11.1 & 9.8 & 9.2 & 9.8 & 10.1 & 10.4 & 10.7 & 9.9 & 9.6 & 9.5 \\
\hline 91.3 & 92.4 & 90.0 & 93.8 & 92.7 & 97.6 & 78.5 & 77.8 & 68.3 & 90.1 & 90.2 & 91.6 \\
\hline 57.0 & 62.6 & 65.4 & 83.2 & 71.8 & 72.5 & 58.0 & 64.3 & 52.1 & 93.3 & 80.1 & 90.2 \\
\hline- & - & - & 15.0 & 14.5 & 15.1 & 14.3 & 14.3 & 13.2 & 16.0 & 15.9 & 14.9 \\
\hline - & - & 一 & 30.4 & 30.6 & 31.7 & 29.9 & 28.3 & 26.4 & .30 .7 & 30.3 & 28.7 \\
\hline 47.3 & 49.6 & 44.9 & 51.1 & 53.5 & 54.4 & 49.1 & 48.8 & 44.3 & 50.4 & 51.0 & 45.7 \\
\hline
\end{tabular}

similar fashion. In both the first and second breedings of the third generation, the average weight of pups in the $2 \times$ group was somewhat less than that for the other groups.

\section{Blood Cell Counts}

Table 4 presents three sets of blood cell counts made on a male and female representative from each of the fifteen groups. Blood cell counts were made on these same animals at 4,10 , and 18 months of age, although by 18 months some of the original members of the group had been sacrificed.

What variations existed among animals on the different diets did not persist over the period studied. Almost without exception every range of values (not shown) for any one count overlapped every other one. The basophiles in all differentials were less than $1 \%$, and platelets were adequate at all times. 


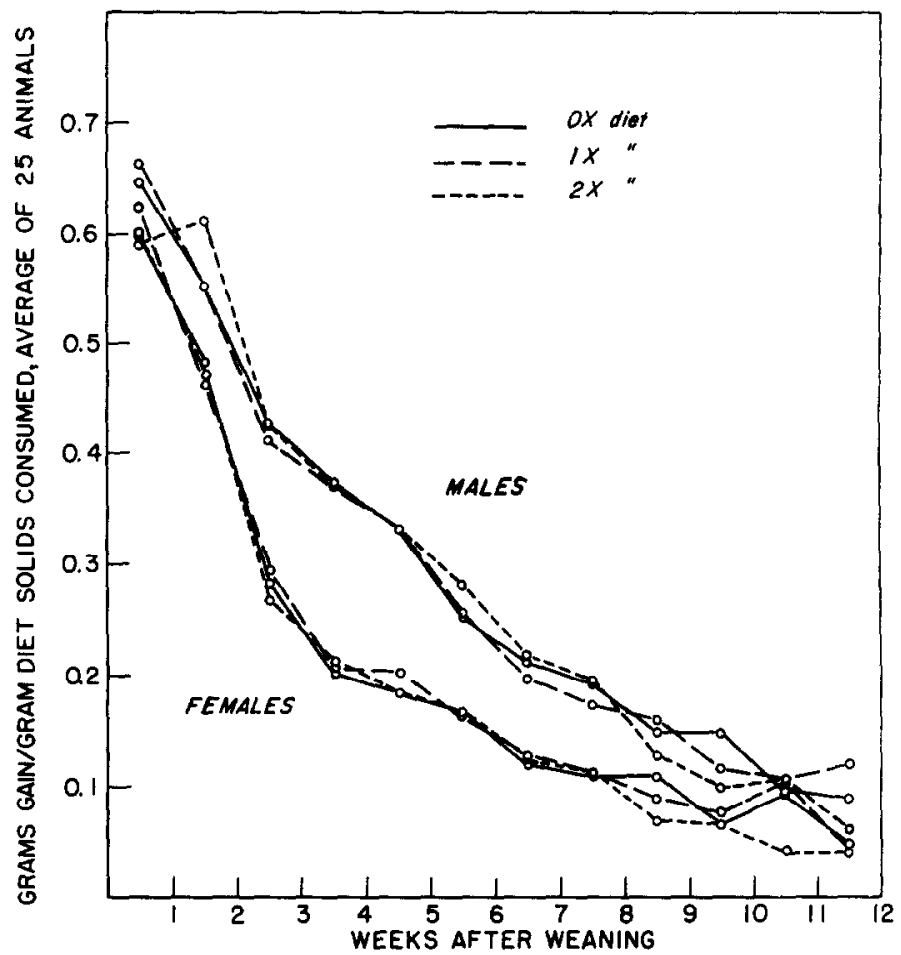

FIc. 2. Efficiency of utilization of food for growth by males and females of the first generation fed diets containing irradiated potatoes $(1 \times$ and $2 \times$ ) relative to those fed the control diet $(0 X)$.

\section{Mortality}

Mortality curves for first- and second-generation males fed each of the three diets are shown in Fig. 3 and for females, in Fig. 4. Each animal is represented by a horizontal bar, the length of the bar corresponding to the animal's age at death. Those animals which died or became moribund after termination of the experiment was begun are indicated by a dagger. There is, of course, no significance to the mortality curve after this point.

The mortality of second-generation animals, controls and experimentals alike, was due principally to a vascular disease (see below), and those remaining after 16 months, although in apparent good health, were sacrificed to complete an evaluation of the extent of the lesions in the entire colony. They had been continued beyond 30 weeks of age on the control 
EFFECT OF IRRADIATED POTATOES ON RATS

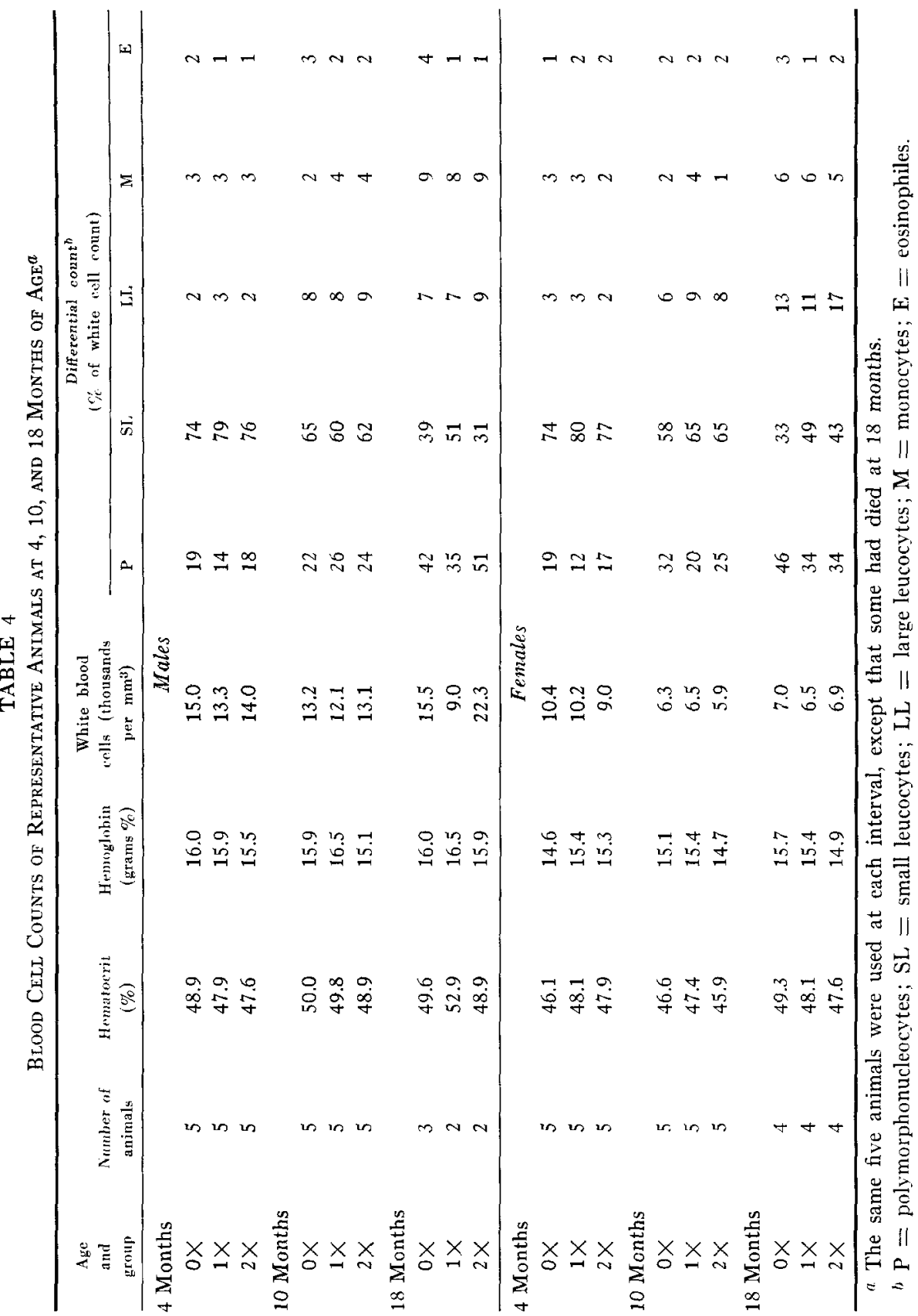




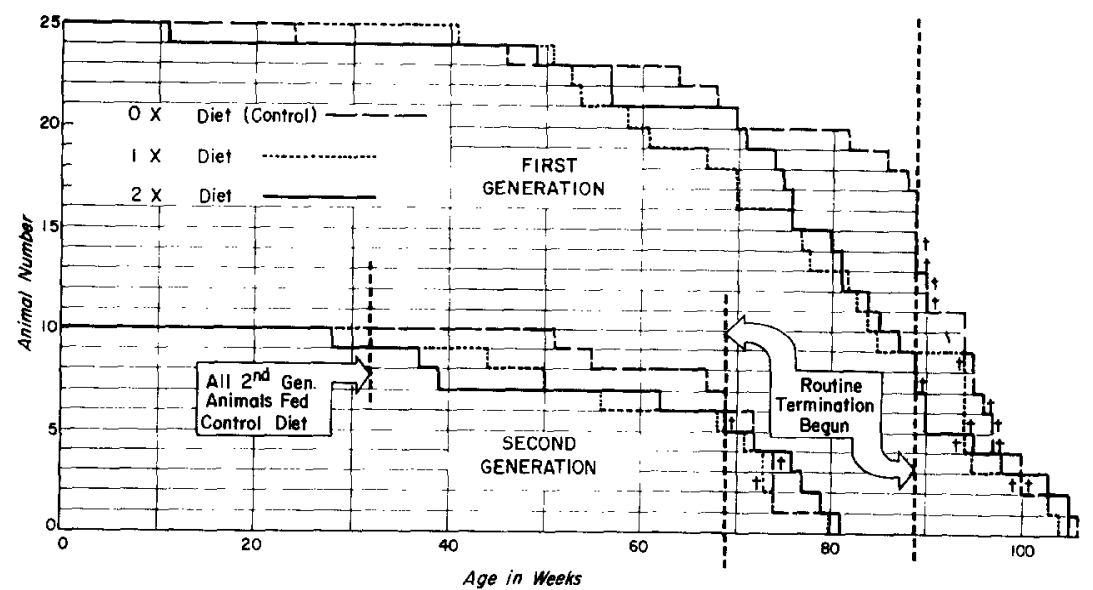

FTg. 3. Survival curve of first-and second-generation males fed irradiated potato diets.

$\dagger=$ Animal died (or required sacrifice) during termination period.

diet, as they were not intended to have been fed the experimental diets beyond this time. The same practice was followed with the third generation, but there was no mortality before the thirtieth week of age, when all were given the control diet and showed little mortality for several months thereafter. The fourth-generation members were transferred to the control diet shortly after weaning, and also showed no significant mortality.

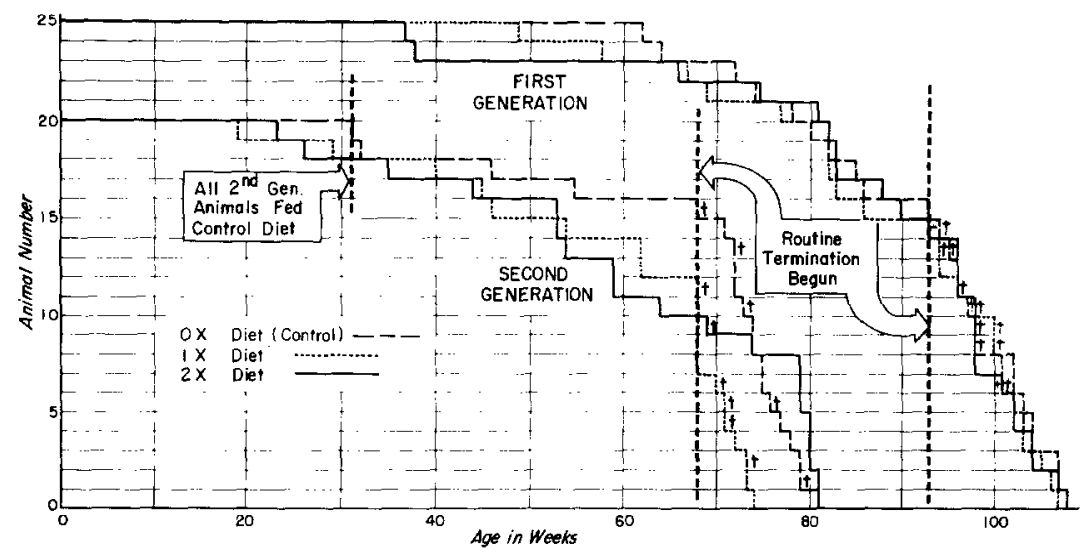

Fig. 4. Survival curve of first- and second-generation females fed irradiated potato diets.

$\dagger=$ Animal died (or requircd sacrifice) during termination period. 
The one important difference among animals on the various diets appeared in the survival rate at 21 months for first-generation members, and at 16 months for second-generation animals. These results are shown in Table 5. In the first generation, the mortality was twice as great among

TABLE 5

Mortality Data for First- and Second-Generation Males and Females during Periods Specified

\begin{tabular}{cccccc}
\hline & \multicolumn{4}{c}{$\%$ mortality of animals at specified ages } \\
\cline { 2 - 3 } \cline { 5 - 6 } & \multicolumn{2}{c}{ First generation } & & \multicolumn{2}{c}{ Second generation } \\
\cline { 2 - 3 } Diet & Males. & Females. & & Males, & Females. \\
\hline $0 \times$ & 39 weeks & 93 weeks & & 69 weeks & 68 weeks \\
\hline $1 \times$ & 32 & 36 & & 30 & 20 \\
$2 \times$ & 64 & 40 & & 50 & 45 \\
& 64 & 40 & & 40 & 50 \\
\hline
\end{tabular}

males on the $1 \times$ and $2 \times$ diets as among those on the control diet, but there was virtually no difference among the female groups. The StudentFisher $t$ test applied to the mortality rate of the male groups revealed no statistically significant difference between any two of them. In the second generation, most of the mortality occurred after the animals had been given the $0 X$ diet. Before the change, however, only one control had succumbed, whereas three had died from the $1 \times$ and three from the $2 \times$ groups. Altogether, after 16 months, the difference between the female groups was rather marked, whereas there was less difference among the male groups.

TABLE 6

Number of Second-Generation Animals (Left of Hyphen) and Number Dead as of 15 October 1957 (Right of Hyphen) According to Whether

Neither, One, or Both Parents Had Died by Same Date, BY Dietary Group

\begin{tabular}{cccc}
\hline & \multicolumn{3}{c}{ Parents dead } \\
\cline { 2 - 4 } Diet & Neither & One & Both \\
\hline $0 \times$ & $18-1$ & $12-1$ & $0-0$ \\
$1 \times$ & $7-0$ & $17-6$ & $6-2$ \\
$2 \times$ & $4-0$ & $22-5$ & $4-2$ \\
\hline
\end{tabular}

Table 6 shows the relation of mortality of second-generation animals to that of their parents by the nineteenth month of the experiment. At this time, the mortality in the second-generation control group reached $7 \%$, that in the $1 \times$ group, $27 \%$, and that in the $2 \times$ group, $23 \%$. The table 
shows that, considering all groups together, the mortality rate of secondgeneration animals, both of whose parents were still living, was only $3 \%$ : of those of whose parents one had died, $32 \%$; and of those of whose parents both had died, $40 \%$. In the control group when one parent had died, it was usually the mother; in the $1 \times$ and $2 \times$ groups it was usually the father, a point ruling out a predominant effect of maternal diet upon the survival of offspring.

It should also be noted from Table 6 that more than half $(60 \%)$ of the second-generation animals in the control group happened to have come from parents both of which were still living, and none from parents both of which had died. In the groups fed the $1 \times$ and $2 \times$ diets, however, only $23 \%$ and $13 \%$, respectively, had come from parents both of which were living, and $20 \%$ and $13 \%$, respectively, had come from parents both of which had died. The parent-generation males and females were random-mated, and it was a matter of chance which particular males and females became parents. It thus appears that second-generation animals fed the irradiated potato diets quite by chance had a larger share of parents whose survival or resistance to disease was low.

\section{Wet Organ Weights}

As part of the necropsy procedure, routine weights were taken of the heart, spleen, kidneys, lungs, liver, and testes. In Table 7 the results appear for each group as the mean percentage with standard deviation of organ : body weight; data from the XL group are included.

In the male groups, there appeared to be a significantly lower ratio of lung to body weight in the controls than with males fed the $2 \times$ diet (statistically significant to the $5 \%$ level). There are no other important differences, even between animals fed the potato diets and the Purina Lab Chow diet.

In the case of the females, the ratio of spleen and lung to body weights appeared significantly lower in the $1 \times$, females than with either the control females or those fed the $2 \times$ diet. Again, there were no important differences between animals fed the two types of diets. The only exceptions to this were that the heart and kidney weights of the females fed the Purina Lab Chow were lower than those of the $0 \times$ females, but not of the $1 \times$ and $2 \times$ females.

\section{Pathologic Changes}

The diseases encountered in this study were similar to those that have been reported in other long-term studies of the rat. The diseases observed 


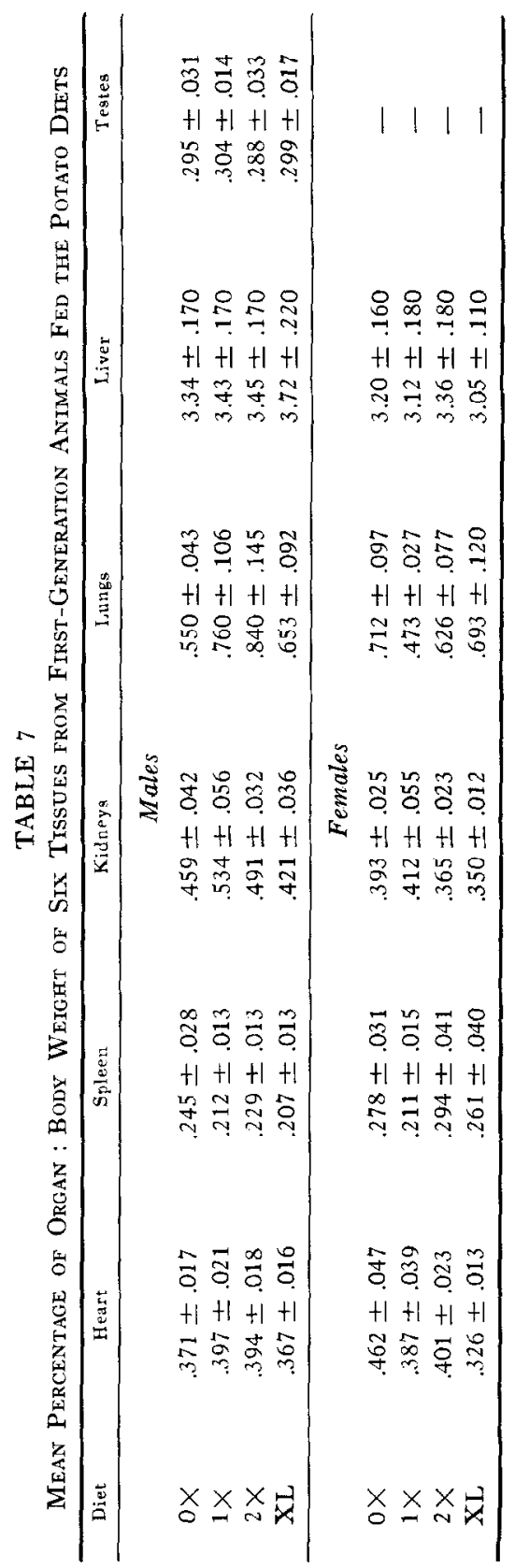


in any one dietary group were of the same types as seen in the other groups. The findings in various organs are outlined below and the incidences of the more common and important conditions are tabulated according to dietary groups.

Brain. Slight cerebral edema and minimal leucocytic infiltration were observed occasionally in each group. Two malignant gliomas were found.

Cardiovascular system. Coronary arteriosclerosis and focal myocarditis were frequently noted, somewhat more often in the $1 \times$ and $2 X$ groups (Table 8). The significance of this apparent difference in incidence is

TABLE 8

Incidences of the Most Common Nonneoplastic Pathologic Processes in the First-Generation Colony ${ }^{a}$

\begin{tabular}{lrrrr}
\hline & \multicolumn{4}{c}{ Dietary group } \\
\cline { 2 - 5 } \multicolumn{1}{c}{ Pathologic process } & $0 \times$ & $1 \times$ & $2 \times$ & $\mathrm{XL}$ \\
\hline Sclerosis of coronary arteries & 6 & 8 & 15 & $3^{b}$ \\
Focal interstitial myocarditis & 7 & 13 & 14 & $1^{b}$ \\
Necrotizing arteritis & & & & \\
$\quad$ Males & 18 & 16 & 18 & 8 \\
$\quad$ Females & 12 & 15 & 9 & 2 \\
$\quad$ Total & 30 & 31 & 27 & 10 \\
Severe bronchiectasis with associated & & & & \\
$\quad$ pneumonitis and abscesses & 5 & 11 & 10 & $5^{b}$ \\
"Vascular nephropathy" & 19 & 11 & 12 & $7^{b}$ \\
Otitis media & 13 & 16 & 15 & $3^{b}$ \\
\hline
\end{tabular}

a Incidences apply to 50 animals (25 males and 25 females) except for XL's as noted.

$b$ Incidence applies to a total of 18 rather than 50 animals.

doubtful since the figures do not reflect a systematic grading and comparison of the lesions. Other abnormalities, including focal endocarditis, mural thrombi, and areas of cartilaginous metaplasia, were less common and of approximately equal incidence in the various groups.

A severe necrotizing arteritis virtually overshadowed the other diseases in each dietary group. The lesions of large visceral arteries were of "periarteritis nodosa" type, while smaller vessels in many areas of the body exhibited necrosis with little exudation. Irradiation of the diet was not a factor in the frequent development of the arteritis (Table 8).

Respiratory system. Inflammatory disease was common in all dietary groups, ranging from the numerous examples of mild tracheobronchitis, to the examples (Table 8 ) of extensive pulmonary parenchymal destruction. 
Digestive system. The most common abnormality of gastrointestinal tract and associated glands was involvement by the necrotizing arteritis described above. Focal chronic pancreatitis, present in each group, paralleled the arteritis. Lipid, in various amounts, was present in the livers of over $80 \%$ of the animals of each dietary group. Eight benign and four malignant neoplasms of the digestive system were noted, with no predilection for any group.

Genitourinary system. A destructive "vascular nephropathy" was seen in each group (Table 8) apparently related to the necrotizing arteritis. Other renal lesions were less common in each group and included focal pyelonephritis, nephrolithiasis, and degenerative fatty infiltration. A single renal neoplasm was found.

The most prevalent gonadal and genital abnormality was involvement by necrotizing arteritis. Chronic endometritis was seen several times in each group, as was suppurative inflammation of preputial or bulbovestibular glands.

Endocrine system. Focal hemorrhage and necrosis were encountered in the adrenals of approximately $10 \%$ of the animals, regardless of diet. Neoplasms of the various glands constituted a frequent finding in each group (Table 9).

Hematopoietic system. Specific abnormalities were not noted, and variations in cellularity of marrow and of lymphoid tissue bore no apparent relation to dietary differences.

Integument. Nonspecific chronic inflammatory lesions, especially of the extremities, were not uncommon in any group. Three cutaneous neoplasms were noted.

Organs of special sense. Otitis media was common in all groups (Table 8) and generally appeared to be of only incidental importance. Ophthalmic disease was rare.

Neoplasms. A total of 106 neoplasms was encountered in 74 animals (Table 9). No real differences between dietary groups with respect to the number of benign or malignant neoplasms were evident.

\section{DISCUSSION}

One disadvantage of irradiation is its enhancement of the rate of decay of foodstuffs which normally spoil by enzymatic rather than microbial action. When the potatoes for this experiment were obtained and irradiated, the conditions under which irradiation of potatoes could be conducted without abnormal decay occurring were not appreciated. One of 
TABLE 9

Incidences of Neorlasms in the First-Generation Colony $a$

\begin{tabular}{lcccc}
\hline & \multicolumn{4}{c}{ Dictary group } \\
\cline { 2 - 5 } \multicolumn{1}{c}{ Nesplasms } & $0 \times$ & IX & $2 \times$ & XL \\
\hline Pituitary tumors & 6 & 8 & $7^{b}$ & $\mathbf{1}$ \\
Adrenal tumors & 4 & 5 & $2^{b}$ & 2 \\
Thyroid adenomas & 6 & 7 & 6 & $\mathbf{1}$ \\
Islet cell adennmas & $\mathbf{1}$ & 4 & 1 & 0 \\
Mammary adenofibromas & $9^{b}$ & $\mathbf{1 1}$ & 8 & 3 \\
Miscellaneous additional neoplasms & & & & \\
$\quad$ Benign & 1 & 2 & 0 & 0 \\
$\quad$ Malignant & 4 & 5 & 1 & 1 \\
Total neoplasms & & & & \\
$\quad$ Benign & 26 & 37 & 22 & 7 \\
$\quad$ Malignant & 5 & 5 & 3 & $\mathbf{1}$ \\
\hline
\end{tabular}

${ }^{a}$ Incidences apply to 50 animals (25 males and 25 females) except for XL's, where the incidence applies to only 18 animals.

$b 1$ malignant.

these conditions is the application of the radiation treatment at the end of the normal potato storage period (March through May) to permit suberization to heal harvest injuries. A second is the use of a minimum dose, e.g., 5000 rads, which inhibits all but a tolerable amount of sprouting. The third is minimum handling of the potatoes after irradiation because suberization and periderm formation, which resist decay, are also inhibited by irradiation. As mentioned above, none of these conditions were met in the supply of the potatnes for this experiment.

The suboptimum condition of the potatoes did not appear to affect the nutritional value of the diet. Growth, food efficiency, and reproductive performance were optimum. With minor exceptions, no differences in these criteria could be traced to irradiation of the potatoes in the diet. The first-generation females fed the $1 \times$ diet appeared to attain a significantly higher body weight than did females fed the other two diets, but this effect did not appear with the females of the second and third generation fed the same diet.

Periodic blood cell counts did not reveal any important difference among the various groups. Practically all ranges of values overlapped. The males fed the $1 \times$ diet maintained a lower white blood cell count throughout most of this period, but considering the small numbers and the variations involved, this is not of statistical significance. With regard to organ weight : body weight ratios, there was only the higher lung weight 
in the males fed the irradiated diets, and this may have been influenced by the increased incidence of respiratory infection in these groups, as noted later.

The mortality rate of both male and female rats fed the irradiated potatoes was consistently, if in some cases only very slightly, higher than those fed the nonirradiated for both the first and second generations. This does not, however, necessarily reflect upon the wholesomeness of the potatoes tested. Not only was there lack of statistical significance, but the greater decay present in the irradiated potatoes may have had a delayed effect on first-generation survival. In the case of the second-generation animals, whose survival could not have been affected by the presence of decay in the diet, it appeared that their mortality was related to that of their parents, rather than to the diet. This point is strengthened by the hereditary influence in the mortality pattern of the first-generation animals. The relation this may have to the occurrence of the necrotizing arteritis in both first- and second-generation animals will be the subject of a subsequent paper (Burns and Abrams). In any case, the additional mortality of $1 \times$ and $2 \times$ first-generation males appeared to be due to a greater incidence of respiratory involvement rather than to necrotizing arteritis, which, as needs to be stressed, was not at all the result of the irradiation treatment.

With reference to the pathologic findings in general, the necrotizing arteritis described above virtually eclipsed the other conditions encountered. A similar process has been described in the rat under various conditions (Wilens and Sproul, 1938; Ingle and Baker, 1953; Masson et al., 1950). The incidence of this disease in group $0 \times$ eliminates consideration of irradiation of the diet as an etiologic factor. Thus, an analysis of these striking lesions will be more properly presented in detail elsewhere (Burns and Abrams).

The apparently greater incidence of severe respiratory disease in groups $1 \times$ and $2 \times$ than in the other groups deserves further consideration. The great susceptibility of the rat to respiratory disease is well known (Ratcliffe, 1949), and these lesions in all degrees of severity were common in each group. The recorded figures take into account only the "end stage" of respiratory disease, and it must be kept in mind that the more frequently observed lesser degrees of inflammation were not as easily compared and were therefore not systematically tabulated, although present in each group. Thus, the significance of the recorded differences in incidence of respiratory infection is questionable. 
The incidence of neoplasms and of middle ear infection was notably great. However, the data in no way suggest any effect of irradiation of the diet in this regard, and, furthermore, these figures are not without precedent in other studies (Nelson and Gowen, 1930; Davis et al., 1956; Crain, 1958; Wright et al., 1940; Gillman et al., 1953).

\section{SCMMARY}

For two years a colony of albino rats was fed diets one-third of which consisted of potatoes which received, for sprout-inhibition purposes, a dose of up to 40 kilorads of irradiation from reactor fuel elements. There were no effects of the irradiation treatment on growth, reproductive performances through four generations, hematology, nor on pathologic changes of these rats. The higher mortality of firstgeneration males and second-generation females fed the diets containing irradiated potatoes is not believed to be attributable to the irradiation treatment per se. Irradiation was not a factor in the unusually high incidence of a necrotizing arteritis resembling "peri-arteritis nodosa" in the first- and second-generation animals.

\section{ACKNOWLEDGMENTS}

The authors wish to express their appreciation for the professional assistance of Kenneth A. Kleyn, Robert L. Kruger, and Robert N. Berkman, D.V.M., for performing the routine examination and gross autopsies of the animals, and for the conscientious assistance of Arthur A. Smiltens who managed the animal colony.

The authors also wish to acknowledge the contribution of Ruth C. Wanstrom, M.D., D. L. Hinerman, M.D., and A. James French, M.D., Chairman, of the Department of Pathology, The University of Michigan Medical School, whose original pathological diagnoses alerted us to the use of this animal colony for a study of hypertensive vascular disease.

\section{REFERENCES}

Brownell, L. E., France, H. O., Harlin, H. A., and Pedersen, S. (1954). Utilization of the gross fission products. Univ. Mich. Eng. Research Inst. Rept. No. 1943-17-P (December).

Brownell, L. E., Gustafson, F. G., Nehemias, J. V., Isleib, D. R., and Hooker, W. J. (1957). Storage properties of gamma-irradiated potatoes. Food Technol. 11, 306-312.

Burns, C. H., and Abrams, G. D. (in preparation). The occurrence of necretizing arteritis in rats fed stored potatoes.

Crain, R. C. (1958). Spontaneous tumors in the Rochester strain of the Wistar rat. Am. J. Pathol. 34, 311-335.

Davis, R. K., Stevenson, G. T., and Busch, K. A. (1956). Tumor incidence in normal Sprague-Dawley female rats. Cancer Research 16, 194-197.

Gillman, J., Gilbert, C., and Spence, I. (1953). Phaeochromocytoma in the rat; pathogenesis and collateral reactions and its relation to comparable tumours in man. Cancer 6, 494-511.

Highlandos, M. E. (1958). Performing a study of the biochemistry of irradiated potatoes under commercial conditions, final report. Quartermaster Food and Container Institute for the Armed Forces, Chicago. 
INCLE, D. J, and BAKER, B. L. (1953). A consideration of the relationship of experimentally produced and naturally occurring pathologic changes in the rat to the adaptation diseases. Recent Progr. in Hormone Research 8, 143-169.

Lf.mman, A.J., Patterson, W. I., Davidow, B., Hagan, E. C., Woodard, G., laug, E. P., Frawley, J. P., Fitzhugh, O. G., Bourke, A. R., Draize, J. H., Nelson, A. A., and Vos, B. J. (1955). Procedures for the appraisal of the toxicity of chemicals in foods, drugs, and cosmetics. Food Drug Cosmetic Law J. 10, 679-748.

Masson, G. M. C., Hazard, J. B., Corcorax, A. C., and Page, I. H. (1950) . Experimental vascular disease due to desoxycorticosterone and anterior pituitary factors; comparison of pathologic changes. A.M.A. Arch. Pathol. 49, 641-664.

Nelsox, J. B., and Gowen, J. W. (1930). The incidence of middle ear infection and pneumonia in albino rats at different ages. $J$. Injectious Diseases 46, 53-63.

Ratcliffe, H. L. (1949). In The Rat in Laboratory Investigation (E. J. Farris and J. Q. Griffith, Jr., eds.), 2nd ed., pp. 519-520. Lippincott, Philadelphia, Pennsylvania.

Sherman, H. C. (1946). Chemistry of Food and Nutrition, 7th ed., p. 629. Macmillan, New York.

Sparrow, A. H., and Christensen, E. (1954). Improved storage quality of potato tubers after exposure to cobalt 60 gammas. Nucleonics 12, No. 8, 16-17.

Warbel, P. E., Bird, H. R., and Baumann, C. A. (1954). Effect of salts on the instability of thiamine in purified chick diets. J. Nutrition 52, 273-283.

Wriens, S. L., and Sproul, E. E. (1938). Spontaneous cardiovascular disease in the rat. II. Lesions of the vascular system. Am. J. Pathol. 14, 201-216.

Wright, A. W., Klinck, G. H., JR., and Wolfe, J. M. (1940). The pathology and pathogenesis of mammary tumors occurring spontaneously in the Albany strain of rats. Am. J. Pathol, 16, 817-834. 